\title{
DEVELOPMENT OF A FULLY INTEGRATED MICRO-POWER SOURCE BASED ON A MICRO-SILICON FUEL CELL AND A MEMS HYDROGEN GENERATOR
}

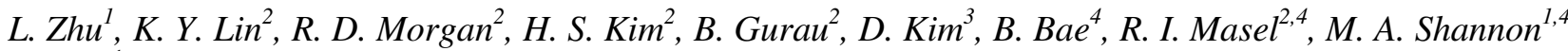

${ }^{1}$ Department of Mechanical Science and Engineering, University of Illinois, Urbana, IL USA

${ }^{2}$ Department of Chemical and Biomolecular Engineering, University of Illinois, Urbana, IL USA

${ }^{3}$ Department of Mechanical Engineering, Sogang University, Seoul, Republic of Korea

${ }^{4}$ Cbana Labs, Inc. Champaign, IL USA

\begin{abstract}
This paper introduces a fully integrated millimeter scale power source based on a micro-silicon fuel cell and a MEMS hydrogen generator. The integrated devices are fabricated from silicon wafers using conventional MEMS fabrication processes. In this design, hydrolysis reaction of calcium hydride and water is used to generate hydrogen and the hydrogen generation rate is controlled by a microfluidic self-regulating mechanism, which can control the hydrolysis reaction based on the load. Design, fabrication, and testing results of a prototype system are described. One of the devices can produce $90 \mu \mathrm{W}$ for $6 \mathrm{hrs}$ with a maximum power of $0.17 \mathrm{~mW}$, and another one can produce $30 \mu \mathrm{W}$ for 26 hours with a total energy density of $100 \mathrm{Whr} / \mathrm{L}$.
\end{abstract}

\section{INTRODUCTION}

Sub-millimeter power sources are needed for micro-sensors, cognitive arthropods, subdermal drug delivery systems, and other applications. Generally, the devices need microwatts of continuous standby power with peak power levels above one milliwatt, and have mission durations of an hour to a few months. At present, sub-millimeter power sources with such power and energy densities have not yet been demonstrated due to constraints on packaging, fuel storage, fuel delivery, and power generation.

To this end, both micro-batteries and micro-fuel cells have been explored to build millimeter scale power sources and some effort have been done to miniaturize the power sources to submillimeter scale. For example, the all solid state thin film lithium battery is the highly promising and mature system already under development by a number of entities with ties to the original work at Oakridge National Laboratory [1,2]. Although planar thin film micro-battery has relatively high power per unit volume, the current density per unit area is low $\left(1-10 \mathrm{~mA} / \mathrm{cm}^{2}\right)$ due to its $\mathrm{cm}$ scale surface area. If the area of the thin film battery is decreased to mm-scale, the maximum power would be in micro-watt range. Therefore, the multiple thin film cells have to be stacked in $\mathrm{z}$ direction to meet the peak power requirement. This process could increase difficulties in fabrication and packaging. A 3-D integrated all-solid-state rechargeable micro-battery has been proposed [3], but it is still at the early stage of development. Recently, microfuel cells have attracted lot of attention to make millimeter scale power sources due to their inherently higher energy and power densities. Most of the current research work is focused on the development of portable PEM fuel cells that meet the demand of portable electronic devices with 1 to $10 \mathrm{~W}$ electric power [4-6]. Several groups have worked on micro-silicon fuel cells [7, 8], but none of them included an integrated micro-fuel storage system to complete an integrated micro-power source.

In this paper, we present for the first time the design, fabrication, and initial testing results of a fully integrated micropower source based on a micro-silicon fuel cell and a MEMS hydrogen generator. The device schematic is shown in Figure 1 and the volume of the whole device is $10.9 \mathrm{~mm}^{3}$. Both of the micro-silicon fuel cell and the MEMS hydrogen generator are fabricated from silicon wafers using standard MEMS fabrication processes, which would enable us to miniaturize the micro system even further to make a sub-millimeter power source. In this work, calcium hydride $\left(\mathrm{CaH}_{2}\right)$ is used as fuel storage due to its high energy density, fast and complete reaction, and low volume expansion [9]. $\mathrm{CaH}_{2}$ is not typically used for large scale mobile hydrogen generators due to its higher weight per hydrogen stored, but here small volumes are more important than low weight. As shown in Figure 1, a microfluidic self-regulating mechanism is integrated into the MEMS hydrogen generator to control the hydrogen generation based on the load. The self-regulating mechanism is fully passive and it does not cause any parasitic power loss. This design provided a feasible approach to build the sub-millimeter power source in the future.

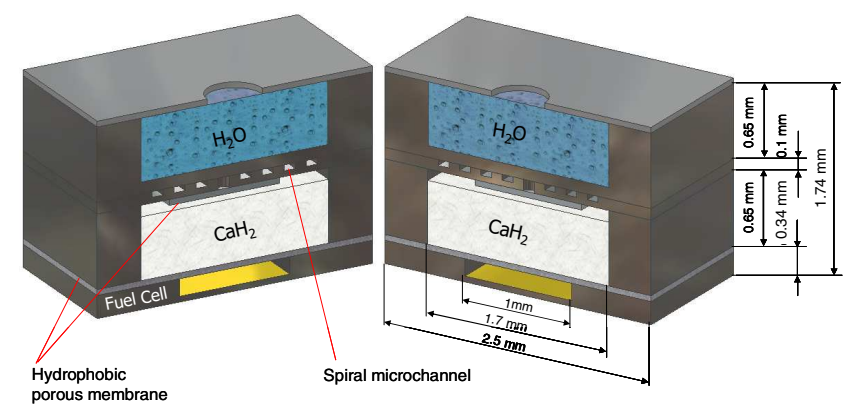

Figure 1: Schematic of the all silicon integrated micro-power source based on self-regulating MEMS hydrogen generator and micro-silicon fuel cell.

\section{FABRICATION}

The micro-silicon fuel cell depicted in Figure 2 is fabricated from a $100 \mathrm{~mm} P$ type boron-doped double sided polished prime $<1-0-0>$ SOI wafer (Ultrasil Corp., Hayward, CA) with $300 \mu \mathrm{m}$ thick handle wafer (0.1-1.0 ohm-cm resistivity), $40 \mu \mathrm{m}$ thick device layer (1-10 ohm-cm resistivity), and $0.5 \mu \mathrm{m}$ thick buried oxide using conventional MEMS fabrication processes. Square windows of $2.4 \mathrm{~mm} \times 2.4 \mathrm{~mm}$ were patterned on the handle wafer (anode side) while a $6 \times 6$ array of circular windows of $100 \mu \mathrm{m}$ diameter and $100 \mu \mathrm{m}$ apart were patterned on the device layer (cathode side). Figure 3 shows the microfabrication processes for making of the Si dies: (A) The native oxide layer was removed by immersion in the buffered oxide etch (BOE) solution and the wafer was cleaned using piranha etch (3:1 sulfuric acid and $30 \mathrm{wt} \%$ hydrogen peroxide); (B) roughly $100 \mathrm{~nm}$ thick silicon nitride layer was grown on both sides of the wafer by low pressure chemical vapor deposition (LPCVD); (C) Photolithography using AZ 4620 photoresist (Clariant Co.) was applied to pattern on the silicon nitride of the handle wafer (anode side) to make the square windows (2.4 mm sides); (D) Dry etching using ICP-DRIE was done to create square windows in the nitride layer on the anode side; (E) Photoresist was removed by photoresist stripper AZ-400T 
(Clariant Co.), then the exposed silicon substrate was wet etched down to the oxide layer using a $35 \%$ potassium hydroxide $(\mathrm{KOH})$ solution at $85^{\circ} \mathrm{C}$ with silicon nitride as the mask; (F) Again, using standard photolithography, a $6 \times 6$ array of circular windows $(100 \mu \mathrm{m}$ diameter) was patterned on the silicon nitride of the device layer (cathode side); (G) Dry etching using ICP-DRIE was done to create the circular windows in the silicon nitride on the cathode side; $(\mathrm{H})$ Dry etching using the $\mathrm{BOSCH}$ process was done to etch $40 \mu \mathrm{m}$ of the exposed silicon substrate down to the oxide layer; (I) Dry etching using a Freon reactive ion etcher system (Freon RIE, PlasmaLab) was done to etch through the oxide layer; (J) Using a DC-Magnetron sputtering system, roughly $150 \mathrm{~nm}$ of gold (50 $\mathrm{nm}$ of chrome as an adhesion layer) was sputtered (everywhere on both sides of the wafer except the openings on both sides) to serve as the current collector.

The membrane electrode assembly (MEA) was directly applied on the fabricated silicon structure as shown in Figure 2. To prepare the MEA, $\sim 28 \mu \mathrm{L}$ of $5 \mathrm{wt} \%$ Nafion ${ }^{\circledR}$ ionomer 1100 EW (Solution Technology Inc.) was applied to the membrane area to fill the channels for proton conduction as well as to serve as an adhesion layer for the anode and cathode catalyst layers. The Nafion ${ }^{\circledR}$ layer was then allowed to dry. Catalyst inks were prepared by dispersing platinum black (HiSPEC 1000, Alfa Aesar) with Nafion ${ }^{\circledR}$ solution, Millipore water, and iso-propanol via sonication. Using the direct paint method, the catalyst inks were painted onto the Nafion ${ }^{\circledR}$ layer of the anode and cathode to form the membrane electrode assembly. The resulting catalyst loading was approximately $20 \mathrm{mg} / \mathrm{cm}^{2}$. In addition to the membrane area, a small amount of catalyst ink was painted onto the gold current collectors to provide electrical connection.

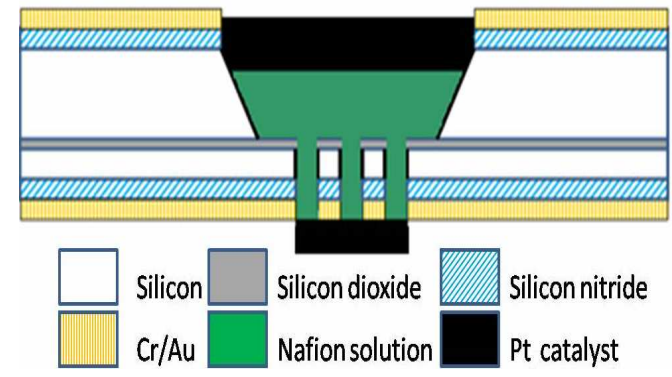

Figure 2: Schematic of Si based hybrid membrane hydrogen fuel cell.
(A)

(B)

(C)

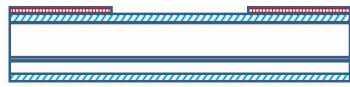

(D)

(E)

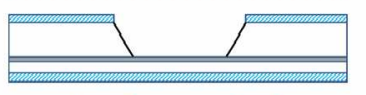

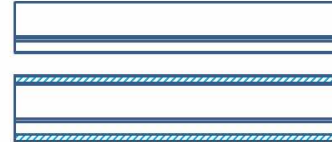

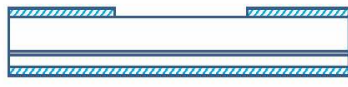

(F)

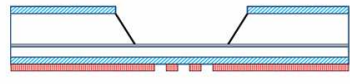

(G)

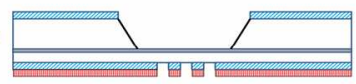

$(\mathrm{H})$

(I)

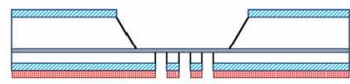

(J)

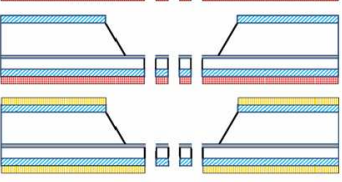

$$
\begin{aligned}
& \text { Silicon } \square \text { Silicon Dioxide WIT Silicon Nitride } \\
& \text { Photo Resist } \quad \text { Gold/Chrome }
\end{aligned}
$$

Figure 3: Microfabrication processes for silicon fuel cell dies.
As shown in Figure 1, the MEMS hydrogen generator was fabricated from three silicon wafers. The water reservoir and hydride reservoir were fabricated from $650 \mu \mathrm{m}$ thick, double side polished prime wafers using ICP-DRIE. The hydride reservoir is $1.7 \mathrm{~mm} \times 1.7 \mathrm{~mm} \times 0.65 \mathrm{~mm}$ and the water reservoir is $1.7 \mathrm{~mm} \times$ $1.7 \mathrm{~mm} \times 0.55 \mathrm{~mm}$ with a $200 \mu \mathrm{m}$ through hole at the corner. The microfluidic self-regulating mechanism was fabricated from a $100 \mu \mathrm{m}$ thick, double side polished prime wafer. A $100 \mu \mathrm{m}$ wide, $30 \mu \mathrm{m}$ deep, and $11.9 \mathrm{~mm}$ long spiral microchannel and a $200 \mu \mathrm{m}$ diameter hole at center end of the spiral microchannel were fabricated on this wafer using ICP-DRIE. To make the surface of water reservoir and microchannel hydrophilic, $0.5 \mu \mathrm{m}$ of silicon dioxide was grown on the surface in an $1100^{\circ} \mathrm{C}$ oxidation tube furnace for $12 \mathrm{hr}$. The water reservoir was aligned and bonded to the microfluidic control layer by adhesive bonding [10] to seal the microchannel and make fluidic connection. A $50 \mu \mathrm{m}$ thick porous hydrophobic PTFE membrane (GE Osmonics Labstore, Minnetonka, MN) was bonded to the control layer to prevent liquid water flowing into the hydride reservoir through the microchannel. Then the hydride reservoir was bonded to the stack (water reservoir and control layer) to complete the fabrication of MEMS hydrogen generator. Finally, $\mathrm{CaH}_{2}$ powder (Aldrich chemical company, St. Louis, MO) was loaded into the hydride reservoir in a nitrogen glove box, then the MEMS hydrogen generator was bonded to the micro-fuel cell separated by a porous PTFE membrane. A photograph of a fabricated device using this approach is shown in Figure 4.

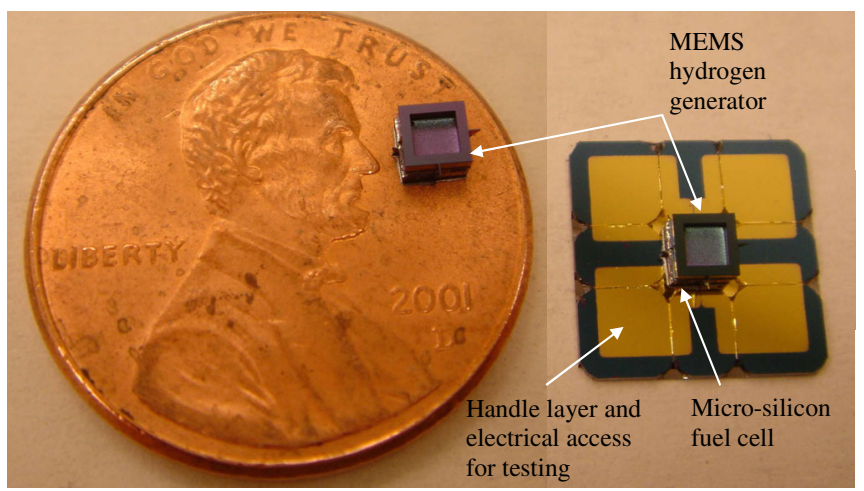

Figure 4: Pictures of the MEMS hydrogen generator and integrated micro power source with micro silicon fuel cell.

\section{RESULTS AND DISCUSSION}

In order to compare the fuel cell performance before and after integration, the micro-silicon fuel cell was tested using a potentiostat (Solartron SI 1287, Solartron Analytical, Hampshire, UK) before integration. Dry hydrogen from hydrogen tank was passed over to the anode, and oxygen was allowed to diffuse to the cathode from ambient air. As shown in Figure 5, the fuel cell has an open cell potential of $0.98 \mathrm{~V}$ and a peak power density of $237 \mathrm{~mW} / \mathrm{cm}^{2}$.

Two prototype devices were fabricated to evaluate the performance of the integrated micro-power source. A hydrogen purging system was built and the device was purged with hydrogen for three cycles to replace trapped nitrogen with hydrogen. The water reservoir was filled with Millipore water and sealed by Parafilm. The device was operated by vapor diffusion. Water flows from the water reservoir into the hydrophilic micro-channel where it contacts the porous hydrophobic membrane. Water vapor diffuses through the membrane and spontaneously reacts with 
$\mathrm{CaH}_{2}$ to release hydrogen $\left(\mathrm{CaH}_{2}+2 \mathrm{H}_{2} \mathrm{O} \rightarrow \mathrm{Ca}(\mathrm{OH})_{2}+2 \mathrm{H}_{2}\right)$. The hydrogen then flows to the anode of the fuel cell. The cathode of the fuel cell is exposed to ambient air to breath oxygen. The polarization curve and power density plot of one of the integrated micro-power sources are shown in Figure 6. The device has an open cell potential of $0.95 \mathrm{~V}$ and a peak power density of $16.8 \mathrm{~mW} / \mathrm{cm}^{2}$. The mass transport limit was reached at $0.3 \mathrm{~V}$ with current density of $48 \mathrm{~mA} / \mathrm{cm}^{2}$. Compared with the fuel cell performance before integration shown in Figure 5, the performance of the integrated device is about one order of magnitude lower. This reduction in power is because the Nafion ${ }^{\circledR}$ membrane was dehydrated by the strongly hygroscopic calcium hydride powder that is located on top of Nafion ${ }^{\circledR}$ membrane. Most of the water in Nafion ${ }^{\circledR}$ membrane from ambient air or from the cathode reaction can permeate through the membrane and react with the calcium hydride to release hydrogen. However, the proton conductivity of Nafion ${ }^{\circledR}$ is related to the water content within it [11]. Low water concentration in Nafion ${ }^{\circledR}$ can result in low fuel cell performance.

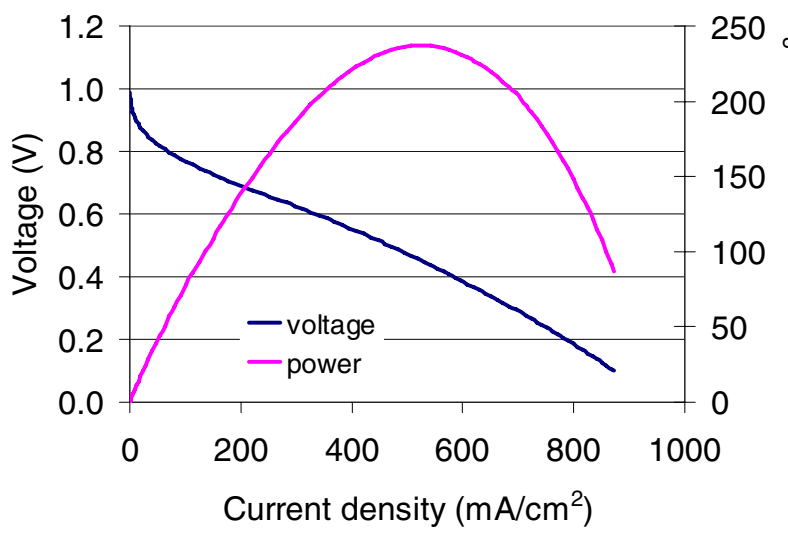

Figure 5: Polarization curve and power density plot of the microsilicon fuel cell before integration. Hydrogen was supplied from a hydrogen tank.

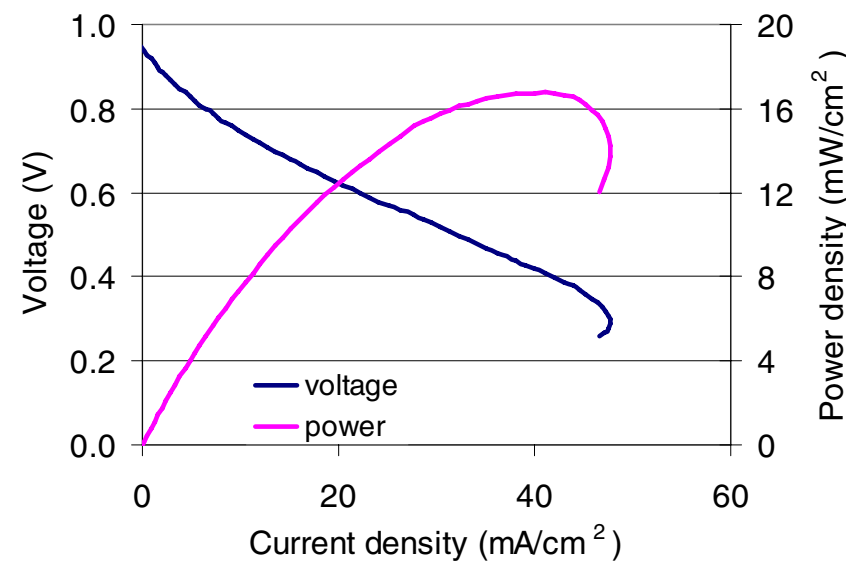

Figure 6: Polarization curve and power density plot of the integrated device. Mass transfer limit was reached at $0.3 \mathrm{~V}$.

Chemical hydrides have been used to generate hydrogen for fuel cell applications for decades [12-14]. In this design, hydrogen production from $\mathrm{CaH}_{2}$ is controlled by a microfluidic self- regulating mechanism. As shown in Figure 7, water flows from water reservoir into the hydrophilic microchannel and a hydrophobic porous membrane can prevent liquid water flowing into the hydride reservoir. Instead, the water vapor diffuses into hydride reservoir through the hydrophobic porous membrane and reacts with the hydride to generate hydrogen. When hydrogen is being consumed at a low rate at the anode under a low load, the water/gas interface is forced to move back to the water reservoir. Therefore, the hydrogen generation rate decreases due to the longer water vapor diffusion length. As hydrogen is consumed by the fuel cell during periods of load, the water-gas interface selfregulates to generate only the required amount of hydrogen. However, this self-regulating mechanism has both minimum and maximum hydrogen generation rate, when the water/gas interface is at the two ends of the microchannel, respectively. The integrated device was operated at $0.8,0.6$, and $0.4 \mathrm{~V}$ alternatively to test the self-regulating mechanism. Figure 8 shows current density plot of the integrated device at each voltage. Although the current density can quickly change when the voltage was changed, it stabilizes in about $30 \mathrm{~min}$. This data indicates that the selfregulating mechanism can regulate the hydrogen generation with the load.

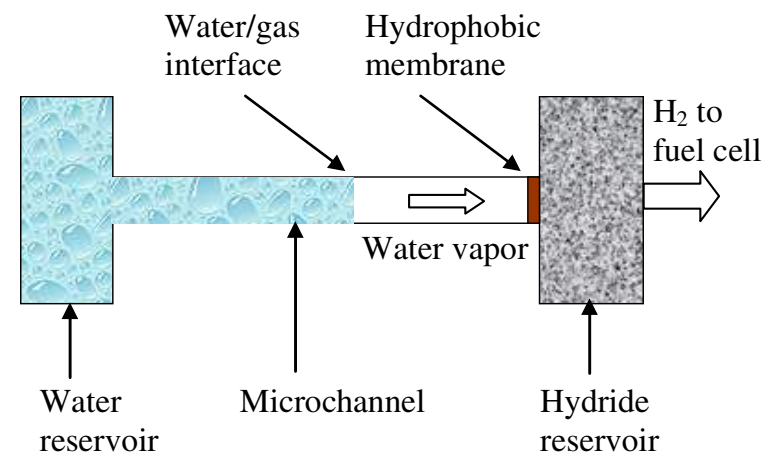

Figure 7: Schematic of the microfluidic self-regulating mechanism for controlling hydrogen generation.

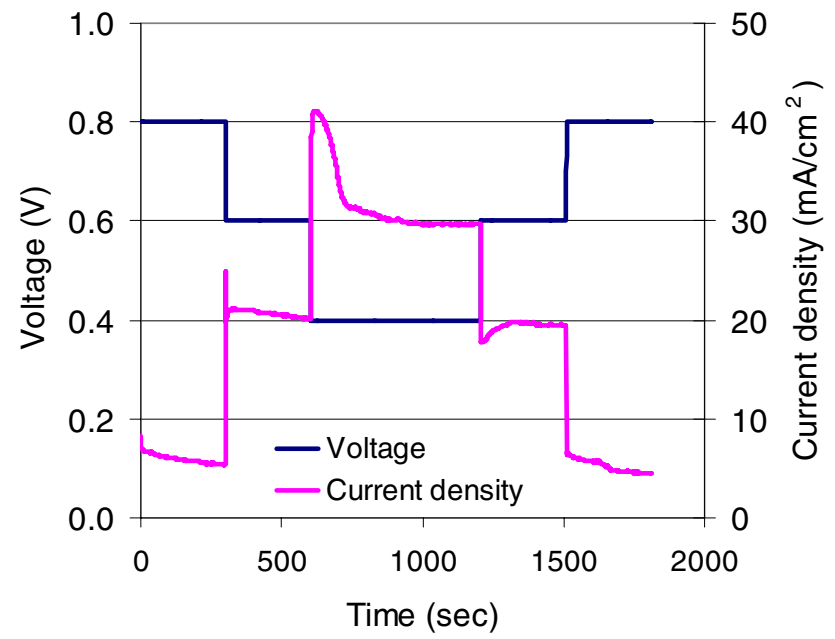

Figure 8: Current density curve of the integrated device at 0.8, 0.6, and $0.4 \mathrm{~V}$ alternatively. The device was operated at each voltage for $30 \mathrm{~min}$. 
Table 1: Summary of the testing results for two fabricated devices based on micro-silicon fuel cell and MEMS hydrogen generator.

\begin{tabular}{|l||c||c||c||c||}
\cline { 2 - 4 } \multicolumn{1}{c||}{} & $\begin{array}{c}\text { Device volume } \\
\left(\mathrm{mm}^{3}\right)\end{array}$ & $\begin{array}{c}\text { Open cell potential } \\
(\mathrm{V})\end{array}$ & $\begin{array}{c}\text { Energy density } \\
(\mathrm{Wh} / \mathrm{L})\end{array}$ & $\begin{array}{c}\text { Maximum power density } \\
(\mathrm{W} / \mathrm{L})\end{array}$ \\
\hline Device 1 & 10.9 & 0.99 & 61.3 & 15.6 \\
\hline Device 2 & 10.9 & 1.01 & 99.9 & 5.1 \\
\hline
\end{tabular}

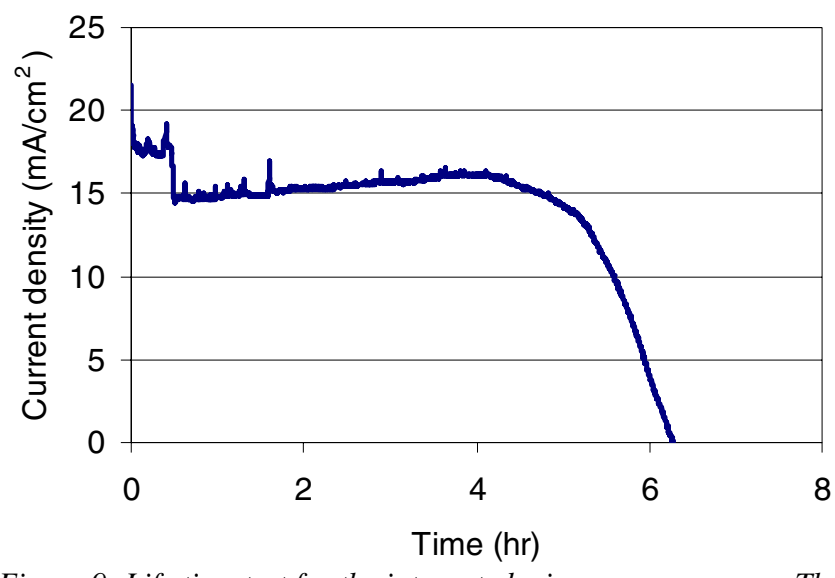

Figure 9: Life time test for the integrated micro power source. The micro fuel cell was running at constant voltage $0.6 \mathrm{~V}$ for more than 6 hours, and the total energy density (based on the volume of the whole device) is $61.3 \mathrm{~W} \cdot \mathrm{hr} / \mathrm{L}$.

Life time tests were also performed at constant voltage $(0.6 \mathrm{~V})$ with the two fabricated devices. As shown in Figure 9, one of the devices ran at $0.6 \mathrm{~V}$ for more than 6 hours until the reaction was complete. Another device ran at $0.6 \mathrm{~V}$ with lower current density for more than 26 hours. A summary of the testing results for two devices is provided in Table 1. Device 2 showed an energy density of $100 \mathrm{Whr} / \mathrm{L}$, which is close to the energy density of current microbatteries [1]. The energy density can be improved if the fuel volume to device volume ratio (32\% for current device) and fuel utilization rate (about $35 \%$ for current device) can be increased. Device 1 has power density of $15.6 \mathrm{~W} / \mathrm{L}$, which is equal to an average power of $0.17 \mathrm{~mW}$. As described previously, the micro-silicon fuel cell can provide maximum power density of $237 \mathrm{~mW} / \mathrm{cm}^{2}$ and the lower power density of the integrated device is due to the drying of the Nafion ${ }^{\circledR}$ membrane. If this problem can be solved in the future design, the integrated device has the ability to provide peak power above 1 milliwatt.

\section{CONCLUSIONS}

A fully integrated micro-power source based on a microsilicon fuel cell and a MEMS hydrogen generator has been demonstrated in this paper. Two integrated devices were fabricated using MEMS fabrication processes. A microfluidic selfregulating mechanism has been successfully integrated into the micro-system, and it can control the hydrogen generation with changes in the applied electrical load. The performance of the integrated device is one order of magnitude lower than the microsilicon fuel cell before integration due to the drying out of the Nafion ${ }^{\circledR}$ membrane by the hygroscopic calcium hydride in contact with it. But one device still has energy density of $100 \mathrm{Whr} / \mathrm{L}$, which is close to the energy density of current microbatteries. The performance is expected to be improved in future designs that mitigate the dryout of the Nafion ${ }^{\circledR}$.

\section{ACKNOWLEDGEMENTS}

This research is funded by the Defense Advanced Research Projects Agency (DARPA) under grant 2007-0299513-000. Any opinions, findings, and conclusions or recommendations expressed in this manuscript are those of the authors and do not necessarily reflect the views of the US Government. Micro-Nano-Mechanical Systems Cleanroom along with Micro and Nanotechnology Laboratory in University of Illinois at Urbana-Champaign provided the microfabrication facilities.

\section{REFERENCES}

[1] N.J. Dudney, Materials Science and Engineering B-Solid State Materials for Advanced Technology, 116 (2005), pp. 245-249.

[2] J.B. Bates, N.J. Dudney, B. Neudecker, A. Ueda, and C.D. Evans, Solid State Ionics, 135 (2000), pp. 33-45.

[3] P.H.L. Notten, F. Roozeboom, R.A.H. Niessen, and L. Baggetto, Advanced Materials, 19 (2007), pp. 4564-4567.

[4] J.D. Morse, International Journal of Energy Research, 31 (2007), pp. 576-602.

[5] K. Cowey, K.J. Green, G.O. Mepsted, and R. Reeve, Current Opinion in Solid State \& Materials Science, 8 (2004), pp. 367-371.

[6] O.J. Adlhart, P. Rohonyi, D. Modroukas, and J. Driller, Asaio J., 43 (1997), pp. 214-219.

[7] T. Pichonat and B. Gauthier-Manuel, Fuel Cells, 6 (2006), pp. 323-325.

[8] K.L. Chu, M.A. Shannon, and R.I. Masel, Journal of the Electrochemical Society, 153 (2006), pp. A1562-A1567.

[9] L. Zhu, D. Kim, M.A. Shannon, and R.I. Masel, in American Chemical Society 234th National Meeting \& Exposition. 2007. Boston, MA.

[10] B.R. Flachsbart, K. Wong, J.M. Iannacone, E.N. Abante, R.L. Vlach, P.A. Rauchfuss, P.W. Bohn, J.V. Sweedler, and M.A. Shannon, Lab on a Chip, 6 (2006), pp. 667-674.

[11] R. O'Hayre, S.W. Cha, W. Colella, and F.B. Prinz, Fuel cell fundamentals 2006, Hoboken, NJ John Wiley \& Sons.

[12] Z.T. Xia and S.H. Chan, Journal of Power Sources, 152 (2005), pp. 46-49.

[13] D. Linden, Handbook of Batteries and Fuel Cells. 1984, New York: McGraw-Hill Inc.

[14] P.P. Prosini and P. Gislon, Journal of Power Sources, 161 (2006), pp. 290-293. 